\title{
Factors Behind the Preference in Contraceptives Use Among Non-pregnant and Sexually Active Women in Benin Republic
}

\author{
Justin Dansou ${ }^{1, ~ *}$, Adeyemi O. Adekunle ${ }^{2}$, Ayodele O. Arowojolu ${ }^{2}$ \\ ${ }^{1}$ Departement of Reproductive Health, Pan African University Institute of Life and Earth Sciences (PAULESI), University of Ibadan, Ibadan, \\ Nigeria \\ ${ }^{2}$ University College Hospital, University of Ibadan, Ibadan, Nigeria
}

Email address:

djustino87@gmail.com (J. Dansou)

${ }^{*}$ Corresponding author

\section{To cite this article:}

Justin Dansou, Adeyemi O. Adekunle, Ayodele O. Arowojolu. Factors Behind the Preference in Contraceptives Use Among Non-pregnant and Sexually Active Women in Benin Republic. Central African Journal of Public Health. Vol. 3, No. 5, 2017, pp. 80-89.

doi: 10.11648/j.cajph.20170305.15

Received: April 1, 2017; Accepted: June 20, 2017; Published: October 10, 2017

\begin{abstract}
Despite the amounting interest in improving access to and utilization of family planning methods, contraceptives prevalence rates remain low in Benin Republic. Rates of increase in contraceptives' prevalence are low and underlying risk factors for use and non-use are not well known. This study investigates similarities and differences in factors associated to contraceptive use by type of method among 6,237 women recruited in 2011/2012 BDHS data using multiple logistic regression models. Most women (78.9\%) involved in the current study did not use any contraceptive during their last sexual activity, $13.6 \%$ were currently using modern contraceptive methods and $7.8 \%$ was using traditional contraceptive methods. Significant covariates for modern contraceptive use were: female education, discussion about FP, number of living children, fertility preference, marital status, household wealth index, sex of household head, religious membership, and the area of residence. Concerning traditional methods use, they were: women's ethnic background, discussion about FP, fertility preference and household wealth index. To improve contraceptives usage especially modern contraceptives, findings suggest, among other: fighting against sociocultural barriers; ensuring female's formal education till secondary; encouraging good health behaviours (ANC follow-up, institutional delivery by skilled attendant, enhancing PNC visits) for women during childbirth and to increase FP education during those check-ups.
\end{abstract}

Keywords: Benin Republic, Contraceptive Preference, Modern Contraceptive, Traditional Contraceptive, DHS

\section{Introduction}

Family planning remains one of the key components of reproductive health programme components set as human right, stated in international law (WHO, 1994) and remain a core component of Sustainable Development Goals (SDG) set for the continuity of the unfinished business of the Millennium Development Goals - MDGs (United Nations, 2014). Access to and effective use of family planning is important tools enabling women to control their own fertility (WHO, 1994) and an effective mean to face effectively the major obstacle of progress that sustained high fertility places in countries where maternal and child mortality remain top priorities (Requejo \& Bhutta, 2015) especially in Sub Saharan Africa (SSA) (Kinney, Kerber, Black, Cohen, \& Nkrumah, 2010). Challenges are even more important in remote regions (Yavinsky, Carolyn, Kristen, \& Jason, 2015) like rural areas with limited health facilities where most of women live in poverty (Worley, 2014). New investment framework especially in family planning in developing countries is one of the most-effective interventions to guide national health and development planning for the next 20 years beyond 2015 by decreasing numerous unintended pregnancies, cause of unsafe induced abortions with its associated risks for mother and infant mortality (Shareen, 2009). Gaining access to family planning services improves maternal health outcomes, and affords women more 
opportunities to become economically active (Blue-Venture, 2015).

Nevertheless, in Benin Republic, reproductive health issues remain among the top priorities for people especially for reproductive age women. At first, none of the MDGs related to health, in particular to reproductive health namely MDGs 4 and 5 was not achieved despite efforts of Benin government and partners. At present, the level of reproductive health indicators, including those relating to family planning are not better in this context. Benin belongs to those countries with high fertility where the population will still be growing until 2050s (PRB, 2012) in spite of fertility decline already begun. The average births per reproductive age women is estimated at 5.8 in 2000 and has declined to about 4.9 in 2014 (UNDP, 2014). The persistence of customs and traditions especially in case of fertility accounts for why fertility is still high among Beninese women. The social organization in this context still favours not only the numerous descendants (high demand of children) among women but also and mostly the polygamy due to the high value placed on kid. Kid is considered as an old age insurance for parents (Ela, 1995) and a means of perpetuation of the descendant (Arugu, 2014). Contraceptive prevalence rate among Beninese women also corroborates with the persistence of customs and traditions in case of fertility in this context. Despite efforts and commitments in improving contraceptives use, the rates of contraceptives use in Benin Republic remain low even though the knowledge of contraceptive methods is widespread across the country (the knowledge of any method 85\%) (INSAE; ICF, 2013). In 2011-2012, the rates of contraceptives use were 14\% (any methods), 9\% (modern methods), and 5\% (traditional methods). A weak appropriation over time of contraceptive use has been noticed. The rates of increase are low. For instance, the modern contraceptive prevalence rate, already low, has increased for only 4 points in 15 years from $5.7 \%$ in 2000 to $9.8 \%$ in 2014 (UNDP 2014). The low-level hides disparities including spatial ones across the country. For instance, in 2011-2012 where on average 9 out of every 100 women were currently using modern contraceptives nationwide, only 3 out of 100 from the area of Mono were noticed (INSAE; ICF, 2013).

\section{Research Goals}

Despite the amounting interest in improving access to and utilisation of family planning services, rates of use remain low with little progresses. Both modern and traditional methods are on use in Benin Republic. Factors associated to contraception use in general and to each kind of methods are scarce especially in Benin Republic. This study attempts to examine similitudes and differences in factors associated with contraception methods use among none-pregnant and sexually active (within the last 4 weeks preceding the survey) reproductive age women recruited for the fourth BDHS of 2011-2012. It identifies factors associated to contraception use in general (any method) and assesses factors associated with the use of each kind of method (traditional and modern).

\section{Literature Review}

The needs for contraceptives use increase with marriage duration especially in SSA countries. In most SSA' societies, at the first marriage or first cohabitation the need for spacing, delaying or even childbirth postponing is low or does not exist at all. The procreation ability of the new couple especially for the woman is to be proven. Thereby, needs for contraception use may come at least after the first childbearing. Contraceptives use is, then, well known as an important determinant of fertility. Most of theoretical frameworks framed for contraceptives use analyses take often into account conceptual frameworks of fertility (Bongaarts, Odile, \& Lesthaeghe, 1984), and that of health care behaviours (Anderson, 1995).

At the empirical level, several studies in low and middle income countries have identified factors that are associated with contraceptives use. However, traditional contraceptives use remains under-examined. Female's age is found to be among the strong predictors of contraceptives use under certain circumstances (Kisaakye, 2013) and with no or weak effect elsewhere (Marrone, Abdul-Rahman, De Coninck, \& Johansson, 2014). As mentioned earlier, contraceptives use is considered as important determinant of fertility, as a result female' $s$ marital status corroborates differences in contraceptives uptake between in-union and non-in union females. The odds of contraceptive use are lower among married (in union) women (Marrone, Abdul-Rahman, De Coninck, \& Johansson, 2014). In urban Senegal, unmarried and sexually active women are more likely to use modern contraceptives than married/in union women (27\% against 20\%) (Sidze, Lardoux, Speizer, Faye, Mutua, \& Badji, 2014). The residence in urban areas is often found to have a considerable positive effect on contraceptives use, both among mothers after delivery during extended postpartum period (Mengesha, Worku, \& Feleke, 2015) and among female adolescents (Marrone, Abdul-Rahman, De Coninck, \& Johansson, 2014).

Under certain circumstances, delivery with the assistance of skilled attendant and postnatal care follow-up were found to have considerable positive influence on contraceptives use in the extended postnatal period (Mengesha, Worku, \& Feleke, 2015).

In some cases, the relationship between female education and contraceptives use is found to be positive (Anasel \& Mlinga, 2014). Under other circumstances, it doesn't make any difference at all (Marrone, Abdul-Rahman, De Coninck, \& Johansson, 2014).

Discussion of family planning contraceptives has been related to its use. Contraceptives use is found to be higher among female who discuss about it (Letamo \& Navaneetham, 2015; Anasel \& Mlinga, 2014). Evidences from Malawi and Kenya have shown that women often engage in repeated discussions about family planning topics before drawing their own conclusions (Paz Soldan, 2004; 
Rutenberg \& Watkins, 1997).

The improving in household wealth index if found to increase the odds of contraceptives use (Anasel \& Mlinga, 2014). Elsewhere, household income's influence disappears (Marrone, Abdul-Rahman, De Coninck, \& Johansson, 2014).

One of the most important issues in advancing family planning's programs especially in sub-Saharan Africa remains sociocultural barriers. Religion's independent effect in contraceptives use has be highlighted in Senegal (Fleischman \& Streifel, 2014), and Tanzania (Anasel \& Mlinga, 2014). The influence of female ethnic background in contraceptives use was also tested (Marrone, Abdul-Rahman, De Coninck, \& Johansson, 2014).

Despite such results evidence are not, however, consistent. For instance, while some studies showed an independent effect (Barber, 2007) of antenatal care follow-up in contraceptives uptake in the postpartum period, other found no or weak association (Mengesha, Worku, \& Feleke, 2015). While Anasel and Mlinga (2014) found differences in contraceptives use according to female's education background, Marrone and al. (2014) found no difference among female adolescents in Ghana across education background. Likewise, the independent effect of other covariates including household wealth index and respondents' ethnic background varies from context to context.

\section{DATA and Methods}

\subsection{Data and Study Population}

Data are from the Benin Republic's Demographic and Health Survey (BDHS) conducted in 2011-2012 (INSAE; ICF, 2013). Using a nationally representative sample the Measure DHS collects data of reproductive age women (1549 years) on several areas such as contraceptive use. This study focused on non-pregnant and sexually active (during the last 4 weeks preceding the interviews) reproductive age women. The study assessed BDHS data from the child recode and individual recode datasets. At total of 16,599 women were interviewed at the survey where 6,237 women were eligible for the current study. Among the study sample $(6,237$ women), $62 \%(3,852)$ gave birth within the preceding five years of the survey.

\subsection{Outcome Variables}

The outcome of this study was utilization of contraceptives devices by women. The study distinguished three different outcomes, all dichotomous ( 1 for "use" and 0 for "non-use"). They were: first "any method", second "modern method", and third "traditional method". The use of contraceptives ("any method") includes both modern and traditional types of contraception. The modern contraceptives include injectable, female sterilization. IUD, pills, diaphragm, Norplant, foam and jelly, male and female condoms. The traditional types of contraception include periodic abstinence and withdrawal. This study considered the current use of contraceptives (within last 4 weeks of interviews) as recorded at the survey.

\subsection{Independent Variables and Measurement}

The study draws correlates from the literature review. They were age group of women at the survey $(15-19,20-24$, 25-29, 30-34, 35-39, 40-44, and 40-45), female education attainment (none, primary, and secondary or above), religion (Traditional, Christian, Islam and no-religion), ethnicity (Fon, Adja, Bariaba, Betamaribe, Dendi, Peulh, Yoa, Yoruba, and other ethnicity), visited by FP workers within the past 12 months of the interview (Yes, and No), discussed FP within the past 4 weeks of the interviews (Yes, and No), number of living children (None, 1-3 children, 4-6 children, and 6 or more), fertility preference (Have another child, undecided, wants no more child, and infecund/sterilized), health behaviours during last childbirth (no formal health behaviour, appropriate health behaviour, some level of health behaviour, and no childbirth/pregnancy). For this covariate (computed with three different indicators: care during pregnancy "antenatal care follow-up", place of delivery, and care during postnatal period "postnatal care follow-up"), no formal health behaviour means women who, during the childbirth of their youngest child below the age of 5 years, had never had any antenatal care (ANC) visits, delivered outside health facility and did not have any postnatal attendance. Appropriate health behaviour encompassed those who met at least the four WHO recommended ANC visits, had institutional delivery, and had been checked for PNC, some level of health behaviours describes the other mothers (with either some level of ANC visits, or either health facility delivery or PNC visits) while no childbirth/pregnancy takes into account those women who did not complete any pregnancy within the 5 preceding years of the survey. Other covariates were: number of other co-wives (none ' 0 ', one ' 1 ', two or more, and not in union), household wealth index (poorest, poorer, middle, richer, and richest), sex of household head (male, female), area of residence (Littoral, Alibori, Atacora, Atlantique, Borgou, Collines, Couffo, Donga, Mono, Oueme, Plateau, and Zou), and place of residence (rural, urban).

\subsection{Analytical Approach}

Data analysis was conducted at three levels. They were univariate, bivariate and multivariate. The univariate involved the use of percentages to describe the study population according to selected independent variables. Bivariate analysis involved cross-tabulation and use of Pearson chi-square test to examine association between each outcome and the explanatory variables. Given the dichotomous nature of each outcome variable, multivariate analyses took the form of binomial logistic regressions performed to examine factors associated to contraceptive use (each outcome) among non-pregnant and sexually active reproductive age women in Benin Republic. Adjusted odds ratios with their corresponding $95 \%$ confidence intervals (95\% CI) were computed to observe the strength. A p-value $\leq 0.05$ was considered statistically significant in this study. 
Statistical analyses were computed using the software $\mathrm{R}$ version 3.3.1 (2016-06-21) for MacBook.

\subsection{Ethical Considerations}

The International Review Board of Macro International and the "Comite National d'Ethique pour la Recherche en Santé (CNRS)" of Benin have all approved the fourth BDHS's tools before the survey were conducted. Participation in the DHS was entirely voluntary and respondents have given their consent preceding the interview. DHS data are freely attainable through DHS MEASURE website. There was no need for ethical approval before using DHS data. Thus, BDHS can be downloaded from the website and is free to use by researchers for further analyses. In order to access the data from DHS MEASURE web site a written request was submitted to DHS MACRO and permission was granted to use the data.

\section{Results}

\subsection{Sample Characteristics and Contraceptive Use}

Table 1 presents study population description by selected characteristics. Among 16,599 women recruited for the fourth BDHS of 2011-2012; 6,237 currently non-pregnant and sexually active were eligible for the current study with $100 \%$ response rate with each selected covariate. The average age of women involved in the current study was 30.67 years. Slightly more than half $(57.98 \%)$ of women were currently living in urban area. Two out of every three $(66.19 \%)$ women were without any formal education. More than half $(59.84 \%)$ declared to be Christian while $14.67 \%$ were from endogenous religion (traditional religion) and $21.13 \%$ were Muslim. There were 8 main ethnic groups represented in the sample. About the half $(48.57 \%)$ of them were from the majority ethnic group (Fon) while the Dendi were the least represented in the sample. Majority of respondents $(84.26 \%)$ had discussions about family planning within the last four weeks preceding the survey while only $6 \%$ declared that they had been visited by FP workers during the last 12 months preceding the survey. About seventy-five percent of respondents had at least a child at the time of the survey. In regard to fertility preference, $60 \%$ declared that they wanted another child while $25 \%$ respondents reported that they wanted to have more children and only $3.6 \%$ of respondents declared that they were infecund or sterilized. Regarding reproductive health behaviours during the childbirth of their youngest child below the age of 5 years, $2.52 \%$ of mothers had no good formal health behaviour (didn't take any antenatal care follow-up, delivered outside health facility, and didn't undergone any postnatal followup), while about two out of every 5 women took appropriate health behaviours (met the minimum 4 ANC visits during pregnancy recommended by WHO, delivered at a health facility, and received postnatal check-up as well), 19.8\% adopted some level of health behaviours, and 38.24\% didn't have any pregnancy during the last five years preceding survey the interview. In the meantime, more than half $(55.35 \%)$ were in monogamous union, $21.48 \%$ were with one other co-wife, $9.64 \%$ with two or more other co-wives, and $13.53 \%$ was without partner. Most women (87.01\%) were currently living in households headed by men. Respondents were almost equally distributed across household wealth indexes. The twelve areas constituting the country were represented in the sample, where the top four (representing more $10 \%)$ being the Oueme $(12.15 \%)$, Zou (11.96\%), Littoral (11.88\%), and Atlantique (11.70\%).

On behalf of contraceptive characteristics most of women $(78.9 \%)$ did not use any contraceptive during their sexual activity within the last 4 weeks preceding the interviews, about $13.60 \%$ of women were currently using modern contraceptive methods and about $7.81 \%$ was using traditional contraceptive methods.

Table 1. Study population description by selected characteristics

\begin{tabular}{lll}
\hline Variable & Frequency & Percent \\
\hline Age group $(n=6,237) ;$ mean=30.67 years & & \\
$15-19$ & 523 & 8.39 \\
$20-24$ & 1,003 & 16.08 \\
$25-29$ & 1,336 & 21.42 \\
$30-34$ & 1,182 & 18.95 \\
$35-39$ & 1,032 & 16.55 \\
$40-44$ & 753 & 12.07 \\
$45-49$ & 408 & 6.54 \\
Education attainment $(n=6,237)$ & & \\
None & 4,128 & 66.19 \\
Primary & 1,061 & 17.01 \\
Secondary or plus & 1,048 & 16.8 \\
Religion $(\mathrm{n}=6,237)$ & & \\
Traditional & 915 & 14.67 \\
Christian & 3,732 & 59.84 \\
Islam & 1,318 & 21.13 \\
No religion & 272 & 4.36 \\
Ethnicity $(n=6,237)$ & & \\
Fon & 3,029 & 48.57 \\
Adja & 972 & 15.58 \\
\hline
\end{tabular}



Sexually Active Women in Benin Republic

\begin{tabular}{|c|c|c|}
\hline Variable & Frequency & Percent \\
\hline Bariba & 488 & 7.82 \\
\hline Betamaribe & 364 & 5.84 \\
\hline Dendi & 218 & 3.5 \\
\hline Peulh & 190 & 3.05 \\
\hline Yoa & 226 & 3.62 \\
\hline Yoruba & 640 & 10.26 \\
\hline Other & 110 & 1.76 \\
\hline \multicolumn{3}{|c|}{ Visited by FP workers last 12 months $(n=6,237)$} \\
\hline No & 5,861 & 93.97 \\
\hline Yes & 376 & 6.03 \\
\hline \multicolumn{3}{|c|}{ Discussed FP last 4 weeks $(n=6,237)$} \\
\hline No & 982 & 15.74 \\
\hline Yes & 5,255 & 84.26 \\
\hline \multicolumn{3}{|c|}{ Number of living children $(n=6,237)$} \\
\hline None $(0)$ & 945 & 15.15 \\
\hline $1-3$ & 2,903 & 46.54 \\
\hline $4-6$ & 2,007 & 32.18 \\
\hline 6 or more & 382 & 6.12 \\
\hline \multicolumn{3}{|l|}{ Fertility preference $(n=6,237)$} \\
\hline Have another child & 3,783 & 60.65 \\
\hline Undecided & 675 & 10.82 \\
\hline Wants no more child & 1,554 & 24.92 \\
\hline Infecund /sterilized & 225 & 3.61 \\
\hline \multicolumn{3}{|c|}{ Health behavior during last childbirth $(n=6,237)$} \\
\hline No formal health behavior & 157 & 2.52 \\
\hline Appropriate health behavior & 2,499 & 40.07 \\
\hline Some level of health behavior & 1,196 & 19.18 \\
\hline No childbirth/pregnancy & 2,385 & 38.24 \\
\hline \multicolumn{3}{|c|}{ Number of other co-wives $(n=6,237)$} \\
\hline None $(0)$ & 3,452 & 55.35 \\
\hline One (1) & 1,340 & 21.48 \\
\hline 2 or more & 601 & 9.64 \\
\hline Not in union & 844 & 13.53 \\
\hline \multicolumn{3}{|l|}{ Household wealth index $(n=6,237)$} \\
\hline Poorest & 1,065 & 17.08 \\
\hline Poorer & 1,223 & 19.61 \\
\hline Middle & 1,320 & 21.16 \\
\hline Richer & 1,366 & 21.9 \\
\hline Richest & 1,263 & 20.25 \\
\hline \multicolumn{3}{|l|}{ Sex of household head $(n=6,237)$} \\
\hline Male & 5,427 & 87.01 \\
\hline Female & 810 & 12.99 \\
\hline \multicolumn{3}{|l|}{ Area $(n=6,237)$} \\
\hline Littoral & 741 & 11.88 \\
\hline Alibori & 367 & 5.88 \\
\hline Atacora & 451 & 7.23 \\
\hline Atlantique & 730 & 11.7 \\
\hline Borgou & 418 & 6.7 \\
\hline Collines & 504 & 8.08 \\
\hline Couffo & 543 & 8.71 \\
\hline Donga & 322 & 5.16 \\
\hline Mono & 324 & 5.19 \\
\hline Oueme & 758 & 12.15 \\
\hline Plateau & 333 & 5.34 \\
\hline Zou & 746 & 11.96 \\
\hline \multicolumn{3}{|l|}{ Place of residence $(n=6,237)$} \\
\hline Rural & 3,616 & 57.98 \\
\hline Urban & 2,621 & 42.02 \\
\hline \multicolumn{3}{|l|}{ Contraceptive use $(n=6,237)$} \\
\hline None & 4,902 & 78.60 \\
\hline Traditional method & 487 & 7.81 \\
\hline Modern method & 848 & 13.60 \\
\hline
\end{tabular}

Source: Authors' own computation (BDHS 2011/2012) 


\subsection{Determinants of Contraceptive Use Among Non-pregnant and Sexually Active Women}

Table 2 presents odds ratios estimates of contraceptive (modern method, traditional method, and any method) use. For contraceptive use in general (regardless of the method: "any method"), except female's age, being visited by FP workers within the preceding 12 months, and the number of living children, all others selected covariates (education attainment, religion, ethnicity, discussion about FP, fertility preference, health behaviour during the last childbirth, number of other co-wives, household wealth index, sex of household head, the department of residence and the place of residence) were statistically significant. On behalf of modern contraceptive methods, risk factors were female education attainment, religion, discussion about $\mathrm{FP}$, number of living children, fertility preference, number of other co-wives, household wealth index, sex of household head, and the area of residence. Regarding traditional contraceptive methods, the determinants were ethnicity, FP discussion, fertility preference, health behaviours during a childbirth of the youngest child below the age of 5 years, household wealth index, and the department of residence.

Women with formal education were more likely to use contraceptive especially modern contraceptive methods compared to uneducated women [for secondary or above education, OR Modern method $=1.68,95 \%$ CI 1.32-2.14; OR any method $=1.65,95 \%$ CI 1.34-2.02]. Muslim women were more likely to use contraceptive especially modern methods compared to those of the endogenous religion [OR modern method $=1.88,95 \%$ CI 1.27-2.78; OR any method $=1.5995 \%$ CI 1.15-2.21]. Betamaribe women were less likely to use contraceptive especially traditional method compared to their homologous from the majority ethnic group, Fon [OR traditional method $=0.1795 \%$ CI $0.06-0.41$; OR any method $=$ 0.36 95\% CI 0.21-0.60]. Against all expectations, women who reported having discussed FP topics the last four weeks before interviews were less likely to adopt contraceptives, regardless of the method [OR any method $=0.3295 \%$ CI $0.27-0.37$; OR modern method $=0.2795 \%$ CI $0.23-032$; OR traditional method $=0.7695 \%$ CI $0.60-0.98]$. Women with at least one living child were more likely to use modern contraceptives [OR 1-3 children $=1.4795 \%$ CI 1.02-2.15]. No difference in traditional contraceptives use according to the number of living children were noticed. Women who reported wanted no more children were more likely to use contraceptives, especially modern methods compared to women who wanted to have another child [OR modern method $=1.695 \%$ CI 1.28 -
2.01; OR any method $=1.3495 \%$ CI $1.10-1.62]$. In reverse, women who were undecided about their fertility preference were less likely to use contraceptive especially modern method [OR any method $=0.7395 \%$ CI $0.57-0.97$; OR modern method $=0.6895 \%$ CI $0.49-0.92]$ and infecund or sterilized women were less likely to use traditional method [OR $=0.48$ 95\% CI 0.22-0.92].

Another important risk factor to contraceptive use was the women's health behaviours during the childbirth of her youngest child aged below 5. Women with formal health behaviours (either appropriate health behaviours or not) and those who did not have childbirth were more likely to use contraceptive. Women's marital status is revealed to play a key role in contraceptives use especially for modern contraceptives uptake. For instance, relative to women in monogamous unions (without any other co-wife) women who were not in union were about two times $(\mathrm{OR}=1.97)$ more likely to use modern contraceptives and 1.67 times more likely to use any contraceptive [OR any method $=1.61$ 95\% CI 1.20-2.15; OR modern method $=1.9795 \%$ CI 1.41 2.77]. The results also show a positive relationship between household's wealth index and the odds of contraceptives use, irrespective of the method type. For instance, the odds of contraceptives use were higher among women in households with middle wealth index compared to their counterpart in households with poorest wealth index [OR any method = 1.64 95\% CI 1.29-2.10; OR modern method $=1.6295 \% \mathrm{CI}$ 1.21-2.19; OR traditional method $=1.4595 \%$ CI 1.02-2.09]. The results also revealed that women in households headed by females were more likely to use contraceptives especially modern contraceptives [OR any method $=1.2595 \%$ CI 1.03 1.53; OR modern method $=1.3495 \%$ CI 1.07-1.67]. Spatial disparities in contraceptives use were also revealed. Surprisingly, women who were currently living in urban area were less likely to use contraceptives compared to those from rural area [OR any method $=0.83 \quad 95 \%$ CI $0.70-0.99$ ]. Similarly, women who lived in Atacora, Collines, and Couffo were more likely to use contraceptives (any method) compared to those who lived in Littoral (Cotonou - main city of the country). In reverse, women who lived in Atlantique, Donga, Ouémé, and Mono were less likely to use contraceptives relative to those who were living in Littoral (Cotonou). For instance, in Mono, the odds of contraceptives use were the lowest (irrespective of the method type) compared to Littoral [OR any method $=0.22$ 95\% CI 0.12-037 ; OR modern $=0.3095 \%$ CI $0.15-0-55$; OR traditional methods $=0.1795 \%$ CI $0.06-0.44]$.

Table 2. Multiple logistic regression models with contraceptives use by kind of method (BDHS: 2011-2012).

\begin{tabular}{|c|c|c|c|c|c|c|}
\hline \multirow{2}{*}{ Variable (reference) } & \multicolumn{2}{|c|}{ Modern } & \multicolumn{2}{|c|}{ Traditional } & \multicolumn{2}{|c|}{ Any method } \\
\hline & OR & $95 \%$ CI & OR & $95 \%$ CI & OR & $95 \%$ CI \\
\hline \multicolumn{7}{|l|}{ Age (30-34) } \\
\hline $15-19$ & 1.12 & $(0.75-1.67)$ & $1.51 *$ & $(0.95-2.40)$ & 1.3 & $(0.93-1.81)$ \\
\hline $20-24$ & 1.12 & $(0.82-1.52)$ & 0.9 & $(0.62-1.32)$ & 1.02 & $(0.79-1.32)$ \\
\hline $25-29$ & $1.27 *$ & $(0.98-1.65)$ & 1.01 & $(0.73-1.41)$ & 1.18 & $(0.95-1.47)$ \\
\hline $35-39$ & 1.14 & $(0.87-1.49)$ & 1.27 & (0.91-1.76) & $1.22 *$ & $(0.97-1.53)$ \\
\hline
\end{tabular}




\begin{tabular}{|c|c|c|c|c|c|c|}
\hline \multirow{2}{*}{ Variable (reference) } & \multicolumn{2}{|l|}{ Modern } & \multicolumn{2}{|c|}{ Traditional } & \multicolumn{2}{|c|}{ Any method } \\
\hline & OR & $95 \%$ CI & OR & $95 \% \mathrm{CI}$ & OR & $95 \%$ CI \\
\hline $40-44$ & 0.82 & $(0.59-1.14)$ & 1.16 & $(0.78-1.73)$ & 0.94 & $(0.71-1.22)$ \\
\hline $45-49$ & $0.67 *$ & $(0.44-1.03)$ & 0.86 & $(0.49-1.45)$ & $0.71 *$ & $(0.50-1.01)$ \\
\hline \multicolumn{7}{|l|}{ Education attainment (None) } \\
\hline Primary & $1.42 * * *$ & $(1.14-1.77)$ & 0.92 & $(0.68-1.22)$ & $1.22 * *$ & $(1.01-1.47)$ \\
\hline Secondary or plus & $1.68 * * *$ & $(1.32-2.14)$ & $1.29 *$ & $(0.95-1.74)$ & $1.65 * * *$ & $(1.34-2.02)$ \\
\hline \multicolumn{7}{|l|}{ Religion (Traditional) } \\
\hline Christian & $1.29 *$ & $(0.98-1.73)$ & 1.11 & $(0.80-1.55)$ & $1.25^{*}$ & $(0.99-1.57)$ \\
\hline Islam & $1.88 * * *$ & $(1.27-2.78)$ & 1.06 & $(0.66-1.72)$ & $1.59 * * *$ & $(1.15-2.21)$ \\
\hline No religion & 1.02 & $(0.61-1.66)$ & 0.7 & $(0.35-1.31)$ & 0.85 & $(0.55-1.29)$ \\
\hline \multicolumn{7}{|l|}{ Ethnicity (Fon) } \\
\hline Adja & 1.09 & $(0.77-1.54)$ & 0.71 & $(0.44-1.11)$ & 0.91 & $(0.67-1.22)$ \\
\hline Bariba & $0.66^{*}$ & $(0.41-1.06)$ & 1.11 & $(0.60-2.05)$ & 0.75 & $(0.50-1.14)$ \\
\hline Betamaribe & 0.63 & $(0.35-1.11)$ & $0.17 * * *$ & $(0.06-0.41)$ & $0.36 * * *$ & $(0.21-0.60)$ \\
\hline Dendi & 0.93 & $(0.53-1.61)$ & 1.48 & $(0.67-3.09)$ & 1.06 & $(0.65-1.71)$ \\
\hline Peulh & 0.61 & $(0.31-1.16)$ & 0.88 & $(0.37-1.96)$ & 0.64 & $(0.36-1.09)$ \\
\hline Yoa & 0.73 & $(0.40-1.32)$ & 0.31 & $(0.05-1.08)$ & $0.59 *$ & $(0.34-1.02)$ \\
\hline Yoruba & 0.98 & $(0.72-1.33)$ & 1.11 & $(0.80-1.54)$ & 1.04 & $(0.81-1.34)$ \\
\hline Autres & 0.84 & $(0.46-1.48)$ & 0.59 & $(0.22-1.31)$ & 0.71 & $(0.42-1.17)$ \\
\hline \multicolumn{7}{|c|}{ Visited by FP workers last 12 months (No) } \\
\hline Yes & 1.19 & $(0.88-1.57)$ & 0.82 & $(0.53-1.23)$ & 1.06 & $(0.81-1.36)$ \\
\hline \multicolumn{7}{|l|}{ Discussed FP last 4 weeks (No) } \\
\hline Yes & $0.27 * * *$ & $(0.23-0.32)$ & $0.76 * *$ & $(0.60-0.98)$ & $0.32 * * *$ & $(0.27-0.37)$ \\
\hline \multicolumn{7}{|c|}{ Number of living children (None: 0) } \\
\hline $1-3$ & $1.47 * *$ & $(1.02-2.15)$ & 0.72 & $(0.46-1.12)$ & 1.11 & $(0.82-1.52)$ \\
\hline $4-6$ & $1.89 * * *$ & $(1.22-2.95)$ & 0.76 & $(0.46-1.28)$ & 1.35 & $(0.94-1.94)$ \\
\hline 6 or more & $1.79 * *$ & $(1.02-3.15)$ & 0.68 & $(0.34-1.35)$ & 1.23 & $(0.77-1.96)$ \\
\hline \multicolumn{7}{|c|}{ Fertility preference (Have another child) } \\
\hline Undecided & $0.68 * *$ & $(0.49-0.92)$ & 0.85 & $(0.60-1.20)$ & $0.73 * *$ & $(0.57-0.93)$ \\
\hline Wants no more child & $1.60 * * *$ & $(1.28-2.01)$ & 0.91 & $(0.68-1.22)$ & $1.34 * * *$ & $(1.10-1.62)$ \\
\hline Infecund sterilized & 1.01 & $(0.60-1.64)$ & $0.48 * *$ & $(0.22-0.93)$ & 0.74 & $(0.47-1.12)$ \\
\hline \multicolumn{7}{|c|}{ Health behavior during last childbirth (No formal health behavior) } \\
\hline Appropriate health behavior & $1.92 *$ & $(0.96-4.42)$ & 2.56 & $(0.92-10.69)$ & $2.17 * *$ & $(1.18-4.38)$ \\
\hline Some level of health behavior & 1.41 & $(0.70-3.27)$ & $3.51 * *$ & $(1.26-14.60)$ & $2.09 * *$ & $(1.14-4.24)$ \\
\hline No childbirth/pregnancy & $1.97 *$ & $(0.97-4.56)$ & $3.00 *$ & $(1.06-12.59)$ & $2.36 * *$ & $(1.28-4.81)$ \\
\hline \multicolumn{7}{|c|}{ Number of other co-wives (None: 0) } \\
\hline One (1) & 0.93 & $(0.75-1.15)$ & 1.2 & $(0.93-1.53)$ & 1.03 & $(0.86-1.22)$ \\
\hline 2 or more & 0.89 & $(0.66-1.18)$ & $0.71 *$ & $(0.47-1.05)$ & $0.79 *$ & $(0.61-1.01)$ \\
\hline Not in union & $1.97 * * *$ & $(1.41-2.77)$ & 0.94 & $(0.61-1.45)$ & $1.61 * * *$ & $(1.20-2.15)$ \\
\hline \multicolumn{7}{|c|}{ Household wealth index (Poorest) } \\
\hline Poorer & 1.17 & $(0.86-1.59)$ & 1.26 & $(0.88-1.83)$ & 1.23 & $(0.96-1.58)$ \\
\hline Middle & $1.62 * * *$ & $(1.21-2.19)$ & $1.45^{* *}$ & $(1.02-2.09)$ & $1.64 * * *$ & $(1.29-2.10)$ \\
\hline Richer & $1.40 * *$ & $(1.02-1.92)$ & 1.32 & $(0.90-1.96)$ & $1.42 * * *$ & $(1.10-1.84)$ \\
\hline Richest & $1.81 * * *$ & $(1.26-2.61)$ & $1.49 *$ & $(0.95-2.35)$ & $1.79 * * *$ & $(1.33-2.43)$ \\
\hline \multicolumn{7}{|l|}{ Sex of household head (Male) } \\
\hline Female & $1.34 * *$ & $(1.07-1.67)$ & 1.01 & $(0.75-1.33)$ & $1.25 * *$ & $(1.03-1.51)$ \\
\hline Area (Littoral) & & & & & & \\
\hline Alibori & 1.46 & $(0.84-2.5)$ & $0.35 * * *$ & $(0.16-0.73)$ & 0.86 & $(0.53-1.38)$ \\
\hline Atacora & $1.88^{*}$ & $(1.09-3.20)$ & 1.31 & $(0.65-2.58)$ & $1.88 * * *$ & $(1.17-3.02)$ \\
\hline Atlantique & $0.56 * *$ & $(0.39-0.80)$ & $0.71 *$ & $(0.47-1.06)$ & $0.59 * * *$ & $(0.44-0.79)$ \\
\hline Borgou & $1.68^{* *}$ & $(1.07-2.60)$ & 0.79 & $(0.44-1.40)$ & 1.34 & $(0.91-1.98)$ \\
\hline Collines & 1.12 & $(0.76-1.63)$ & $1.46^{*}$ & $(0.96-2.23)$ & $1.39 * *$ & $(1.02-1.90)$ \\
\hline Couffo & $2.06 * * *$ & $(1.33-3.21)$ & 0.9 & $(0.50-1.60)$ & $1.60 * *$ & $(1.09-2.35)$ \\
\hline Donga & 1.02 & $(0.58-1.76)$ & 0 & $(0.00-0.00)$ & $0.52 * *$ & $(0.31-0.86)$ \\
\hline Mono & $0.30 * * *$ & $(0.15-0.55)$ & $0.17 * * *$ & $(0.06-0.44)$ & $0.22 * * *$ & $(0.12-0.37)$ \\
\hline Oueme & $0.71 *$ & $(0.50-1.00)$ & $0.34 * * *$ & $(0.21-0.54)$ & $0.50 * * *$ & $(0.37-0.67)$ \\
\hline Plateau & 0.75 & $(0.47-1.18)$ & 1.14 & $(0.69-1.85)$ & 0.91 & $(0.63-1.32)$ \\
\hline Zou & 0.9 & $(0.63-1.29)$ & $0.66^{*}$ & $(0.42-1.01)$ & $0.77 *$ & $(0.57-1.04)$ \\
\hline Place of residence (Rural) & & & & & & \\
\hline Urban & 0.87 & $(0.70-1.06)$ & 0.85 & $(0.65-1.09)$ & $0.83 * *$ & $(0.70-0.99)$ \\
\hline
\end{tabular}

Significance code: $* * *, 1 \% ; * *, 5 \% ; *, 10 \%$

Source: Authors' own computation (BDHS 2011/2012) 


\section{Discussion}

There are differences and similitudes in factors associated to contraceptives use by method type among non-pregnant and sexually active women in Benin Republic.

In agreement with past studies (Sidze, Lardoux, Speizer, Faye, Mutua, \& Badji, 2014), our study revealed that women who were not in marital union were more likely to use contraceptives, especially modern methods, compared to those in monogamy union. Possibly when there is a fear of possible stigma of childbirth outside union (or even fear of STI), contraceptive use appears to be the right option for sexually active women in Benin Republic. No statistically significant difference was noticed between women living in monogamy and those living in polygamy concerning contraceptive use. Contraception is a key determinant of fertility. Similar to other studies, the present study found that the number of living children and the fertility preference are among key determining factors for contraceptives use among Beninese women. The use of contraceptives, especially of modern methods, occurs mostly among women with at least a living child. Such finding indicates the key role Beninese still places on kids. Similarly, women who desire no more children were more likely to use contraceptive compared to those who were undecided or infecund/sterilized.

This study reported that religion affects contraceptive usage as other past studies did (Anasel \& Mlinga, 2014; Fleischman \& Streifel, 2014). Another key socio-cultural factor found with independent influence was women's ethnicity. Such results corroborate the influence of social and cultural practices on family planning accounting for the higher level of fertility in Benin Republic. However, elsewhere ethnic background didn't make any difference (Marrone, Abdul-Rahman, De Coninck, \& Johansson, 2014). There is a need to strength education and communication policies for contraceptives use.

Reports from Malawi and Kenya have shown that women often engage in repeated discussions about family planning topics before drawing their own conclusions (Paz Soldan, 2004; Rutenberg \& Watkins, 1997). In Benin, such discussions do not favour contraceptives use. It is possible that myths surrounding the use of modern family planning methods could have influence the Beninese women's decision to use family planning methods. Report from past studies in Accra have shown that women are concerned about the side effects of contraceptive methods including the fact that the usage of contraceptive would have delay fertility or complete infertility (Hindin, Mc Gough, \& Adanu, 2013). In order to address why discussion about FP oppose contraceptives use among Beninese women, more in-depth information on what kind of discussion women often hold in addition to their perceptions and attitudes are needed. However, living in household headed by women favour contraceptives use, especially modern methods among Beninese women. The decision power linked to household head position, when given to women, encourages contraceptives use. Such finding concurs past studies' results on the key role that women play in their environment, especially regarding modern contraceptive use (Okigbo, Mc Carraher, Chen, Gwarzo, Vance, \& Chabikuli, 2014).

In our study, we also found a positive relationship between contraceptive use (regardless of the method type) and the household wealth index as previously reported (Anasel \& Mlinga, 2014). The lack of financial capabilities prevents our study respondents from contraceptive use. Efforts towards free contraceptives provision are needed to increase contraceptives uptake among lower economic class women. The current study also revealed differences in contraceptive use across women's educational background in Benin Republic were especially in term of modern contraceptives. A positive and linear relationship was noticed. The importance of this covariate was reported by past studies, too (Anasel \& Mlinga, 2014). The acquisition of formal education increases women's knowledge about contraceptives. Moreover, educated women are more likely to seek economic and financial independence and thereby are on a need to combine two important necessities: family life and professional life. As a result, contraception appears to be among effective solutions. Also, contraceptives usage is an effective means which girls can use if they want to stay for long in school in today's changing environment where sexual tries become more and more important.

The age differences found in this study is in agreement (at $10 \%$ level of significance) with the findings by Kisaakye (2013), unlike others studies where no or weak association was found (Marrone, Abdul-Rahman, De Coninck, \& Johansson, 2014). However, the influence of this covariate needs to be further explored. Another important key factor to contraceptives use revealed by the current study pertains to the women's health behaviours during pregnancy, delivery and postnatal period. The frequency of attendance of ANC services, institutional delivery and PNC follow-up check-ups increase women's odds of contraceptive use in extended postnatal period (Barber, 2007). Increase FP education during antenatal care and childbirth (from pregnancy to postnatal period) will increase women's contraceptives use in the extended postnatal period.

Spatial variations in contraceptives use among our study participants were noticed. Against all expectations, the odds of contraceptive uptake (any method) were lower among women living in urban areas. Such finding disagrees with previous studies (Mengesha, Worku, \& Feleke, 2015; Marrone, Abdul-Rahman, De Coninck, \& Johansson, 2014). Possibly the misinformation and myths during discussion about contraceptives were higher among Beninese women living in urban area since it was negatively associated to contraceptives use. Concerning the area of residence, related findings, however, were mostly against expectation, too. In reverse to expectations, women from some places like Couffo, Collines Borgou, and Atacora have higher risks of contraceptives use compared to those living in Littoral (Cotonou). The lowest usages of contraceptives were 
recorded among women from Mono, where contraceptive prevalence rate was even at its lowest level (3\%). Among others, there is a need to pay special attention to FP policies in some areas like Mono, Ouémé, Donga, and in Atlantique.

\section{Conclusion}

Despite recent efforts in improving knowledge, access to and use of contraceptives, the rates of contraceptives use in Benin Republic remain low, and the rates of increase are low. Non-negligible number of women still practicing traditional contraceptives. An understanding of the factors that influence utilization of contraceptives especially the similarities and the differences in associated risks factors by the method type is helpful in identifying possible reasons for use and non-use of each type of method. While the results of the current study clarify such aspects, further researches, especially qualitative investigations, are needed for more understanding of the reasons preventing women from contraceptives uptake. For instance, further qualitative research investigating women's perceptions, attitudes, knowledges, and experiences in the contraceptives practice will be helpful to illuminate, among other, the finding from this study showing that women who declared having discussed contraceptive topics (the preceding 4 weeks of the interviews) were less likely to practice them (irrespective of the method type) compared to those who did not discuss them. Such an understanding can inform the Ministry of Health and other stakeholders and decision makers in Benin Republic in the formulation of national and local policies and programs to increase contraceptives use. To improve contraceptive use especially modern contraceptives, the results also suggest a need to empower women, strengthen female's education, and integrate FP education in maternal health services (ANC follow-up, health facility delivery, and PNC visits).

\section{References}

[1] WHO. International Conference on Population and Development Cairo Declaration on Population and Development. 1994.

[2] United Nations. The road to dignity by 2030: ending poverty, transforming all lives and protecting the planet. Synthesis report of the Secretary-General on the post-2015 sustainable development agenda. 2014.

[3] Requejo, JH and Bhutta, ZA. The post-2015 agenda: staying the course in maternal and child survival. Arch Dis Child 2015; 100 (Suppl1):. doi: 10.1136/archdischild-2013-305737, pp. $76-81$.

[4] Kinney, M; Kerber, K; Black, R; Cohen, B; Nkrumah, F. SubSaharan Africa's Mothers, Newborns, and Children: Where and Why Do They Die. 2010, PLoS Med 7:e1000294. doi:10.1371/journal.pmed.1000294.

[5] Yavinsky, RW, et al. The Impact of Population, Health, and Environment Projects: A Synthesis of Evidence. 2015, Working Paper. Washington, DC: Population Council, The Evidence Project.
[6] Worley, H. \$5 More Per Person Annually Could Save Millions of Mothers and Children. 2014, Population Reference Bureau.

[7] Shareen, Joshi. "Reproductive health and economic development: what connections should we focus on?". 2009, Research brief, poppov \& PRB, p. 5p.

[8] Blue-Venture. Working across sectors for real change. [Online] 2015. [Cited: 11 June 2015.] http://www.blueventures.org/conservation/community-health/.

[9] PRB. "PRB Discuss on line: Africa's Demography Challenges". Population Reference Bureau. 2012.

[10] UNDP. Human Development Report 2014 Sustaining Human Progress: Reducing Vulnerabilities and Building Resilience. United Nations Development Program. 1 UN Plaza, New York, NY 10017, USA: s.n., 2014.

[11] Ela, JM. Fécondité, structures sociales et fonctions dynamiques de l'imaginaire en Afrique Noire . [book auth.] H GERARD and V PICHE. Sociologie des populations, Montréal, PUM/AUPELF-UREF. 1995.

[12] Arugu, LO. Social indicator and effects of divorce in African societies. November 2014, The Business and Management Review, Vol. 4, pp. pp374-383.

[13] INSAE; ICF. Enquête Démographique et de Santé du Bénin 2011-2012. . Calverton, Maryland, USA : INSAE et ICF International., Institut National de la Statistique et de l'Analyse Économique (INSAE) et ICF International. 2013.

[14] Bongaarts, J, Odile, F and Lesthaeghe The proximate determinants of fertility in sub-Saharan Africa.. 1984, Population and Development Review, Vol. 10, pp. 511-37.

[15] Anderson, R. Revisiting the behavioral model and access to medical care: does it matter. 1995, Journal of Health Soc Behav, Vol. 36(1), pp. 1-10.

[16] Kisaakye, P. Determinants of unmet need for contraception to space and limit births among various groups of currently married women in Uganda. 2013. 1st Annual International Interdisciplinary Conference, AIIC 2013, 24-26 April, Azores, Portugal.

[17] Marrone, Gaetano, et al. Predictors of Contraceptive use Among Female Adolescents in Ghana. 1, 2014, African Journal of Reproductive Health, Vol. 18, pp. 102-109.

[18] Sidze, E M; Lardoux, S; Speizer, I S; Faye, C M; Mutua, M M; Badji, F. Young Women's Access to and Use of Contraceptives: The Role of Providers' Restrictions in Urban Senegal. International Perspectives on Sexual and Reproductive Health, 40(4):176-183, doi: 10.1363/4017614. 2014.

[19] Mengesha, Zelalem, Birhanu, Worku, Gebeyehu, Abebaw and Feleke, Senafikish, Amsalu. Contraceptive adoption in the extended postpartum period is low in Northwest Ethiopia. 2015, BMC Pregnancy \& Childbirth (DOI 10.1186/s12884015-0598-9), Vol. 15.

[20] Anasel, Mackfallen, G. and Mlinga, Upendo J. Determinants of contraceptive use among married women in Tanzania: Policy implication. no 2 Supplement, July 2014, African Population Studies, Vol. 28 , pp. 978-988.

[21] Letamo, G and Navaneetham, K. Levels, trends and reasons for unmet need for family planning among married women in Botswana: a cross-sectional study; 5:e006603. doi:10.1136/bmjopen-2014-006603. 2015, BMJ Open. 
[22] Paz Soldan, V. A. How family planning ideas are spread within social groups in rural Malawi. 4, 2004, Studies in Family Planning, Vol. 35, pp. 275-290.

[23] Rutenberg, N and Watkins, SC. The buzz outside the clinics: Conversations and contraception in Nyanza Province, Kenya. . . 4, 1997, Studies in Family Planning, Vol. 28, pp. 290-307.

[24] Fleischman, J and Streifel, C. Strategic Partnerships to Advance Family Planning Lessons from Senegal. 2014, Global Health Policy Center.

[25] Barber, S. Family planning advice and postpartum contraceptive use among low-income women in Mexico. 2007, Int Fam Plan Perspect, Vol. 33(1), pp. 6-12.

[26] Hindin, MJ, McGough, LJ and Adanu, RM. Misperceptions, misinformation and myths about modern contraceptive use in Ghana. 2013, The journal of family planning and reproductive health care / Faculty of Family Planning \& Reproductive Health Care, Royal College of Obstetricians \& Gynaecologists.

[27] Okigbo, Chinelo C., et al. Unmet Need for Contraception among Clients of FP/HIV Integrated Services in Nigeria: The Role of Partner Opposition. 2014, African Journal of Reproductive Health. 18[2]: 134-143. 